\title{
Clients' Perceptions of the Quality of Care in Mexico City's Public-Sector Legal Abortion Program
} CONTEXT: In 2007, first-trimester abortion was legalized in Mexico City. Limited research has been conducted to un-
derstand clients' perceptions of the abortion services available in public-sector facilities.

METHODS: Perceptions of quality of care were measured among 402 women aged 18 or older who had obtained abortions at any of three public-sector sites in Mexico City in 2009. Six domains of quality of care (client-staff interaction, information provision, technical competence, postabortion contraceptive services, accessibility and the facility environment) were assessed, and ordinal logistic regression analysis was conducted to identify the domains that were important in women's overall evaluation of care.

RESULTS: Clients gave overall services a high rating, with a mean of 8.8 out of 10. In multivariate analysis, overall ratings were higher among women who said the doctor made them feel comfortable (odds ratio, 3.3), the receptionist was respectful (1.7), the staff was very careful to protect their privacy (2.5), they had received sufficient information on self-care at home following the abortion and on postabortion emotions (1.9 and 2.0, respectively) and they felt confident in the doctor's technical skill (2.5). Rating site hours as very convenient (2.4), waiting time as acceptable (2.8) and the facility as very clean (1.9) were all associated with higher overall scores. Compared with women who had given birth, those who had not rated the services lower overall (0.6).

CONCLUSION: Efforts to improve patient experiences with abortion services should focus on client-staff interaction, information provision, service accessibility, technical competence and the facility environment. The most highly significant factor appears to be whether a doctor makes a woman feel comfortable during her visit. International Perspectives on Sexual and Reproductive Health, 2011,37(4)191-201, doi: 10.1363/3719111

Induced abortion is common in Mexico, but it has historically placed women's lives and health at risk because it is often performed clandestinely in unsafe conditions. ${ }^{1}$ Between 1990 and 2005, abortion-related complications were the fifth-leading cause of maternal mortality nationally, and the third-leading cause in Mexico City specifically. ${ }^{2}$ In 2006, a national study estimated the rate of hospitalization for the treatment of induced abortion complications at 5.7 per 1,000 women aged $15-44$, a $6 \%$ increase over the rate in $1990 .^{3}$

Mexico's abortion laws vary by state, but in most states abortion is illegal except in a few limited circumstances, such as when a woman's life or health is in danger, or if a fetus has serious genetic malformations. The only circumstance in which abortion is legal across all states of Mexico is when a pregnancy is the result of a rape. ${ }^{4}$ Even when abortion is legally permitted, it can be difficult for women to obtain services because of bureaucratic hurdles, a lack of knowledge about the law or provider refusals to perform a legal abortion. ${ }^{1,4,5}$

Recognizing the illegality of abortion as a cause of unsafe procedures that resulted in high maternal mortality and morbidity, ${ }^{6}$ the Mexico City legislature decriminalized first-trimester abortion in 2007. The legislature also took steps to ensure that abortion services would be accessible to women regardless of their ability to pay; the law stipulated that at public hospitals that are part of the Mexico City Ministry of Health, abortion services would be provided free of charge for Mexico City residents and on a sliding fee scale for residents of other states. ${ }^{4}$

Nevertheless, this progressive legislation may not be enough to assure women of access to high-quality, confidential services. For example, in India, where abortion has been legal since 1971, studies indicate that unlicensed services remain an important source of abortion care for the population, particularly in rural areas, because of limited access to licensed abortion services and the poor quality of those services. ${ }^{7}$ As a consequence, unsafe abortions in India are estimated to contribute to $8 \%$ of all maternal deaths, according to a national study conducted between 2001 and 2003. ${ }^{8}$ Similarly, in South Africa, where abortion has been legally available since 1997, illegal abortions also continue to occur. Research exploring why South African women seek illegal abortions cites lack of information on the abortion law and available services and fears of being treated poorly by the staff working at sites delivering legal abortion care. $^{9}$

The World Health Organization recommends that clients' perspectives of the quality of services be studied as part of routine monitoring and evaluation of abortion ser-
By Davida Becker, Claudia DíazOlavarrieta, Clara Juárez, Sandra G. García, Patricio Sanhueza and Cynthia C.Harper

At the time this article was written, Davida Becker was postdoctoral fellow, Bixby Center for Global Reproductive Health, University of California, San Francisco, USA. Claudia DíazOlavarrieta is researcher, and Clara Juárez is researcher, both at Instituto Nacional de Salud Pública, Tlalpan México DF. Sandra G. García is country director, Population Council México, Coyoacan México DF. Patricio Sanhueza is reproductive health coordinator, Secretaría de Salud, Gobierno del Distrito Federal, México DF. Cynthia C. Harper is associate professor, Department of Obstetrics, Gynecology and Reproductive Sciences, Bixby Center for Global Reproductive Health, University of California, San Francisco, USA. 
vices, ${ }^{10}$ as they may be linked to important outcomes. ${ }^{11}$ For example, low acceptability of legal services may lead women to seek care from unsafe providers or to self-induce abortions, resulting in abortion-related morbidity and mortality. Service quality may also affect such factors as clients' willingness to return to services and to practice postabortion contraception, and may even affect clients' health outcomes..$^{12}$ If they do not receive sufficient information during their visits, clients may not know what complications to look out for or what contraceptive options are available to them. ${ }^{13}$ If they are treated poorly, they may not return for follow-up visits. Furthermore, clients may share their negative experiences with friends and family, thereby creating a negative reputation for services in the community. ${ }^{9}$ Studies of quality improvement in postabortion care have found that interventions to improve abortion providers' contraceptive counseling can result in increases in women's uptake of contraception and reduce repeat abortion. ${ }^{14,15}$

Research to monitor the implementation and impact of the 2007 reform can provide essential information to the Mexico City Ministry of Health, as well as to other countries considering similar policy reforms. * Although past research has investigated women's experiences with abortion care and postabortion care in Mexico, there have been few studies since the reform. ${ }^{16,17}$ Previous studies in Mexico that investigated access to legal abortion in cases of pregnancy following rape revealed that the process to obtain a legal abortion was highly bureaucratic and timeconsuming. Furthermore, women were often exposed to misinformation and judgmental treatment during the process from both health care providers and public officials who were responsible for approving legal abortions; some women reported that attempts were made to dissuade them from having an abortion. $5,18,19$

Other studies in Mexico that have investigated women's experiences with postabortion care prior to the recent reform have discovered problems with the accessibility of the services, the information women receive during visits, the provision of contraception, the interpersonal treatment from the staff and the respect shown for women's privacy. ${ }^{12,20,21}$ For example, a study in Mexico City comparing different models of postabortion care in six hospitals that are part of the Mexican Institute of Social Security (IMSS) found that between 6\% and 32\% of women were not offered any contraceptive method. In addition, fewer

*There has been a backlash against this law in many Mexican states, and similar abortion policy reforms are unlikely to occur in the near future in other states. Since the reform was passed in 2007, 17 of the 31 states of Mexico have approved amendments to their state constitutions defining a fertilized egg as a person with a right to legal protection, and several other states are moving in this direction (source: Grupo de Información en Reproducción Elegida, Reformas constitionales que protegen la vida desde la concepción/fecundación, 2008-2011, <http://www.gire.org.mx/ contenido.php?informacion=70>, accessed June 29,2011).

†The program is not operational at other public-sector sites in Mexico City that receive federal funding, for example, facilities of the IMSS and the Institute for Social Security and Services for State Workers. These publicsector providers are responsible for providing health care to public and private sector employees. than half of women received information about potential complications following the procedure and how to care for themselves at home. ${ }^{12}$

In the current study, we sought to learn about client perspectives on the quality of care in Mexico City's publicsector legal abortion program following the legalization of first-trimester abortion. Past research has found that patient satisfaction with abortion care is associated with such service quality factors as the interpersonal treatment of clients by the staff ${ }^{22-24}$ and the information provided, 22,25 as well as with such client social and demographic factors as age, parity, marital status and education..$^{22,25,26-28}$ Aspects of the abortion visit have also been associated with satisfaction with abortion care, specifically, the procedure type, the gestational age, the type of care site and whether clients are able to choose the type of abortion procedure. ${ }^{24,27,29,30}$ In our study, we hypothesized that women's overall evaluation of abortion care would be a function of the quality of care they received; social and demographic factors; and abortion visit features, including procedure type, site of care and whether clients were offered a choice of procedure.

\section{METHODS \\ Study Setting and Procedures}

We conducted our research at three public-sector sites offering abortion services in Mexico City. The legal abortion program in Mexico City is operational only at publicsector facilities run by the Mexico City Ministry of Health, ${ }^{\dagger}$ which provides health services to the low-income and uninsured population. All of the sites are Mexico City Ministry of Health hospitals or health centers. At the time of our study, 13 public-sector sites provided abortion services. ${ }^{31}$ We selected the sites in our study to reflect the three types of public-sector sites where abortion services are available: a general hospital, a maternity hospital and a primary health center. In each category, we selected the highest-volume site that could participate. For one category, the highest-volume site was unable to participate, so we selected the second-highest-volume site. Service statistics from 2009 indicate that the total number of women who received legal abortions at the three sites in our study was slightly more than 1,000 women at the general hospital, nearly 2,000 women at the maternity hospital and more than 7,000 women at the primary health center. Together, the three sites accounted for $61 \%$ of all abortions performed in the public sector in 2009. Forty-three percent of all abortions were performed at the primary health center, which is the highest-volume site. ${ }^{31}$ The maternity hospital and the primary health center are located in the same administrative municipality of the city, about one block from each other; the general hospital is located in a different municipality in the southwest.

All sites offer both surgical and medication abortion procedures. Surgical procedures are typically performed with manual vacuum aspiration or electric aspiration; relatively few procedures are done with sharp curettage. Med- 
ication abortions are performed with a regimen of misoprostol alone.* The protocol for a medication abortion is two doses of $800 \mathrm{mcg}$ of misoprostol taken by mouth four to six hours apart, with the first dose administered in the facility and the second taken at home. ${ }^{32}$ Women undergoing medication abortion also receive a handout with instructions on how to take the pills at home and what to do in case of complications. Medication abortion clients are scheduled for a follow-up visit, usually 15 days after they take the first dose, to confirm the completion of the procedure. In the event of an incomplete procedure, the woman is given a repeat dose of misoprostol or a surgical abortion in the facility.

The type of abortion procedure women receive is typically based on gestational age, determined by ultrasound. The Ministry of Health generally offers women with a pregnancy of fewer than nine weeks' gestation medication abortions and those with pregnancies of 9-12 weeks' gestation surgical abortions ${ }^{33}$ (medication abortions tend to be more efficient and less costly, as they require less staff time and do not require the use of an operating room). Although this is the official protocol, providers vary in how they determine the type of abortion procedure and, in some circumstances, women are offered a choice of procedures. All women receiving care are provided with detailed counseling, including information about the abortion procedure, potential side effects and contraceptive options.

The protocol for delivering abortion care is similar across the three study sites, but the format of counseling differs somewhat. At the maternity hospital and the primary health center, women seeking abortion receive both group and individual counseling; at the general hospital, however, all counseling is done individually. At the facilities where group counseling is offered, it is used to provide women information about the abortion procedure and family planning methods. The facilities also vary with respect to how abortion services are integrated into the site. At the primary health center, the abortion service has a separate, dedicated space, whereas at the hospitals, the abortion service is provided within the obstetrics and gynecology section of the hospital, in a space that is shared with other services.

We conducted our study with a sample of women receiving abortion care at any of the study sites between September and December 2009. Women were eligible to participate in the study if they were aged 18 or older and were seeking a first-trimester abortion. All data collection took place while the women were at the facilities. Women receiving surgical procedures were recruited on the day of their abortion, after their appointment was over but before they left the facility. Women receiving medication abortions were recruited after their follow-up appointment. The procedure differed from that for surgical abortions because the study questionnaire had to be filled out after the abortion was complete, and medication abortion patients did not know if their abortion was complete until after their follow-up appointment, two weeks after their initial appointment.

Three female study interviewers, recent undergraduates in clinical psychology who were currently enrolled in graduate studies, were responsible for recruiting participants. They underwent comprehensive training in interviewing techniques prior to beginning fieldwork. The interviewers visited the sites nearly every day that abortion services were offered. Interviewer hours varied by site; in the hospitals (which have clinic hours from 7:00 a.m. to 3:00 p.m. on weekdays), interviewers attended in the morning for approximately four hours, and at the primary health center (which has clinic hours from 7:00 a.m. to 9:00 p.m. on weekdays), the interviewer attended for approximately six hours, from the late morning to the late afternoon. While the interviewer was on site, staff members informed all eligible women about the study. Any woman who was interested in learning more could meet with the study interviewer in a private space at the site after her appointment. After explaining the purpose of the study, the interviewer obtained verbal consent if the woman wished to participate and then administered the survey, which took approximately 20 minutes. Participation was anonymous. After completing the survey, each woman was provided with a gift card to a local store, worth approximately US\$10. The study protocol was approved by the Mexico City Ministry of Health and by the University of California, San Francisco Committee for Human Research.

\section{Sample Size}

We calculated the sample size for the survey so that we could detect an expected difference of 15 percentage points in women's overall rating of care for those seen at the primary health center versus those seen at either of the hospitals, with $80 \%$ power. We assumed that women at the primary health center would give the overall service a higher score (85\%) than women at the hospitals (70\%) because the health center environment is a specialized center that delivers only abortion care, whereas the hospitals treat a much wider array of health conditions. With these assumptions, we determined we needed 134 participants per recruitment site. At each site, we attempted to recruit half the sample as medication abortion patients and half as surgical abortion patients, but this proved challenging. Although we achieved a nearly balanced sample at the primary health center, which has the highest abortion patient volume (49\% medication and 51\% surgical), our sample at the two hospitals was skewed toward one procedure or the other. At the maternity hospital, we recruited more medication abortion patients than surgical abortion patients (64\% medication and 36\% surgical), while at the general hospital, the opposite was true (70\% surgical and 30\% medication).

*Mifepristone was registered in Mexico in early 2011 and is not yet being used to perform medication abortions in the public sector. The Ministry of Health recently completed a feasibility study to determine whether a mifepristone protocol could be used in the future. 


\section{Questionnaire}

According to two published frameworks, ${ }^{34,35}$ we conceptualized abortion service quality as consisting of the following six domains: client-staff interaction, information and counseling, technical competence, postabortion contraceptive services, accessibility and the facility environment. We included questions to measure each of the identified domains, adapted from questions used in previous patient experience studies, including one on women's perceptions of abortion care. ${ }^{23,36}$ We developed the survey instrument in English, and a native Spanish-speaker from Mexico then translated it into Spanish. We pilot tested the survey and our recruitment procedures with 12 women seeking abortion care services at the study sites to ensure that women understood the questions and perceived them as relevant.

\section{Measures}

The outcome variable measured women's overall evaluation of the service and was based on the following survey item: "Using any number from 0 to 10 , where 0 is the worst care possible and 10 is the best care possible, what number would you use to rate the health care you received at this clinic or hospital?" Because only 38 women gave the services a score of 7 or less, we recoded responses into the following categories: score of 7 or less, score of 8 , score of 9 and score of 10 .

The independent variables included measures of the domains of quality of care, women's social and demographic characteristics and characteristics of the abortion visit. For the domains of quality of care, we measured client-staff interaction by asking women to rate the extent to which each of the following had occurred: The doctor had made them feel comfortable, the nurse and the receptionist had treated them with respect and dignity, and the security guard had used a rude tone or manner with them. The response options for these questions were on a fourpoint scale: "yes, definitely," "yes, somewhat," "no" and "no, not at all."* We measured perceptions of confidentiality by asking women how careful the staff had been with their personal and private information; the possible response options were "very careful," "somewhat careful" and "not careful."

To measure the adequacy of information and counseling at the visit, we asked women to rate the information they had received from the staff about the abortion procedure ("sufficient" or "insufficient"), to report whether they had received sufficient information about how to take care of themselves at home following the abortion ("yes" or "no") and to report whether a staff member had spoken with them about how they might feel emotionally after the abortion ("yes" or "no"). To measure women's perceptions of clinicians' technical competence, we asked women to rate whether they had confidence in the technical skills of

\footnotetext{
*The response choices for the question on the security guards, which was negatively worded, were as follows: "yes, definitely," "yes, somewhat," "no" and "no, (s)he was nice."
}

the doctor who had attended them on a four-point scale from "yes, definitely" to "no, not at all," and to report how well they felt the staff had managed their pain during the abortion (the staff "could have done more to control pain," "did enough to control pain" or "I did not experience any pain"; the one participant who reported not experiencing any pain was grouped with those who said the staff had done enough.)

To measure postabortion contraceptive services, we asked women whether a staff member had talked with them about family planning at the visit ("yes" or "no"), and whether they had been offered a method of family planning ("yes" or "no"). Accessibility was measured by asking the women how easy it had been for them to obtain their appointment at the facility (on a four-point scale from "very easy" to "very difficult"), how convenient they found the sites' hours of operation (on a four-point scale from "very convenient" to "very inconvenient") and how they felt about the total time spent at the facility the day of the abortion procedure ("acceptable," "I should have spent less time" or "I should have spent more time"). Finally, to assess the facility environment, we asked women to rate the cleanliness of the facility on a four-point scale from "very clean" to "very dirty," and to report whether they had seen antichoice protesters outside the facility at any of their appointments ("yes" or "no"). Among participants who reported seeing antichoice protesters, we asked a follow-up question regarding whether they had felt bothered by the protesters.

We recoded all variables measured on scales as dichotomous measures, grouping participants who selected the most positive rating (e.g., the group who selected "yes, definitely" when asked if the doctor had made them feel comfortable) and comparing these participants to those who selected other response options. We chose this cut-point because we expected to encounter mostly positive ratings of the services, as is common in patient satisfaction research. ${ }^{37}$ If we had opted to compare all participants who responded positively to those who responded negatively, we would have had limited variability in our data. Our decision to dichotomize our variables as we did was an attempt to identify individuals who, despite feeling services were good, still felt improvements could be made. ${ }^{37}$ We also suspected that some of the respondents might have been reluctant to express a clearly negative viewpoint.

Data on social and demographic characteristics included age, parity, marital status, education, state of residence and previous induced abortion. Abortion visit characteristics included the type of abortion procedure received, the gestational age at the time of the abortion (based on what the doctor told the woman), the sex of the doctor who performed the abortion, the type of care site (general hospital, maternity hospital or primary health center), whether the current procedure was carried out to complete an incomplete abortion (based on women's reports) and whether women reported being offered a choice regarding the type of abortion procedure. 


\section{Analysis}

Client data collected from the questionnaires were entered into an Epi Info database, and double data entry was done on a $10 \%$ random sample of the questionnaires to check the accuracy of the data entry process. We transferred data to Stata version 9.2 for statistical analysis. We first carried out a descriptive analysis by estimating proportions and means for the indicators of the six quality of care domains. We next estimated bivariate ordinal logistic regression models to determine associations between the quality of care measures, women's social and demographic characteristics, abortion visit features and women's overall rating of service quality. Finally, we estimated a multivariate ordinal logistic regression model that included variables from our bivariate analysis that were significant at the $\mathrm{p}<.10$ level. The ordinal regression models tested whether particular variables were associated with the odds of reporting a higher versus lower overall rating of service quality, as measured using the four-category outcome variable. We checked for collinearity between variables and found that being offered a method of contraception was collinear with receiving counseling on contraception, so we therefore included only the measure of whether women were offered a contraceptive method in our final model. For all analyses, we considered a p value of less than .05 as statistically significant. In our final model, we tested whether the assumption of proportional odds was valid using the Brant test. ${ }^{38}$ The Brant test statistic was not significant $(\mathrm{p}=.94)$, indicating that ordinal logistic regression was an appropriate model for the data.

\section{RESULTS}

Of the 597 eligible women invited to participate in our study, 402 took part, for a participation rate of $67 \%$. The mean age of the participants was 25.5 years (Table 1 ). Forty percent of the sample had less than a high school education. Most women were residents of Mexico City, but 29\% lived elsewhere in Mexico, most commonly in the state of Mexico (not shown). More than half of the women in the sample were single, while $42 \%$ were married or in a civil union. Fifty-seven percent had children, and 9\% reported a previous induced abortion.

Forty-eight percent of women in the sample had a medication abortion, the remainder a surgical procedure. The mean gestational age at the time of the abortion was 8.4 weeks. The type of procedure received varied by gestational age. Among clients who received medication abortions, the mean gestational age was 7.1 weeks, compared with 9.6 weeks among clients who received surgical abortions ( $\mathrm{p}<.001$; not shown). Thirteen percent of respondents indicated that the current abortion procedure was carried out following an incomplete medication abortion. When asked whether they had been offered a choice regarding the type of abortion procedure they could receive, $46 \%$ indicated that they had been. The proportion reporting they were offered a choice of procedure did not vary by gestational age, procedure type, site, or the client's
TABLE 1. Percentage distribution of women aged 18 or older who obtained legal abortions in Mexico City, by selected social and demographic and abortion visit characteristics, 2009

Characteristic

$\%$ or mean $(\mathrm{N}=402)$

SOCIAL AND DEMOGRAPHIC

Mean age (yrs.)

$25.5(6.0)$

High school graduate

Yes

No

60

Residence

Mexico City

Other

Marital status

Unmarried

Married/in civil union

42

Parity

0

$\geq 1$

43

57

Previous induced abortion

Yes

No

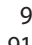

ABORTION VISIT

Site

General hospital

Maternity hospital

Primary health center

33

33

33

Abortion procedure

Medication abortion

Surgical abortion

48

52

Mean gestational age (wks.)

Current procedure was follow-up to an

incomplete medication abortion

Yes

No

13
87

Client reported being offered a choice of

abortion procedure

Yes

No

46
54

Sex of the doctor who performed the abortion

Male

Female

52

48

Total

100

Notes: Unless otherwise noted, data are percentages. Figures in parentheses are standard deviations. Percentages may not add to 100 because of rounding.

social and demographic characteristics. Forty-eight percent of women were attended by a female doctor. When asked about their preference for the sex of the doctor performing abortion care, 57\% reported having no preference, while 39\% said they preferred a female doctor and $3 \%$ said they preferred a male doctor (not shown). Of those who reported a preference ( $\mathrm{N}=171), 68 \%$ were seen by a doctor of their preferred sex.

Overall, women gave their care high ratings (Table 2, page 196). The mean overall rating of care (on a 0-10 scale) was 8.8 , with a standard deviation of 1.1. Women also gave high scores to their interactions with the staff. 
TABLE 2. Percentage distribution of abortion patients, by rating of quality of abortion care, according to six domains of care

\begin{tabular}{lr} 
Measure & $\%$ or \\
& $(\mathrm{N}=$ \\
\hline OVERALL SERVICE QUALITY & \\
Mean overall quality ratingt & 8.8 \\
& \\
CLIENT-STAFF INTERACTION & \\
Doctor made woman feel comfortable & 85 \\
Yes, definitely & 10 \\
Yes, somewhat & 5 \\
No/no, not at all & \\
& \\
Nurse treated woman with respect and dignity & 92 \\
Yes, definitely & 6 \\
Yes, somewhat & 3 \\
No/no, not at all &
\end{tabular}

Receptionist treated woman with respect and dignity Yes, definitely

Yes, somewhat

No/no, not at all

$\%$ or mean

$\mathrm{N}=402)$

$8.8(1.1)$

5

Staff care with woman's personal and private information

Very careful

Somewhat careful

Not careful

Security guard used rude tone or manner

Yes, definitely/yes, somewhat

No

No, (s)he was nice

26

54

INFORMATION AND COUNSELING

Staff provided sufficient information about the abortion procedure

Yes

No

93

Staff provided sufficient information about self-care following abortion

Yes

No

87

13

Staff talked with woman about how she might feel emotionally after abortion

Yes

No

48

52
Measure

$\%$ or mean

$(\mathrm{N}=402)$

TECHNICAL COMPETENCE

Woman felt confident in technical skills of doctor

Yes, definitely

Yes, somewhat

No/no, not at all

87

2

Perception of staff management of pain during abortion

Could have done more to control pain 13

Did enough to control pain

POSTABORTION CONTRACEPTIVE SERVICES

Staff member talked with woman about family planning

Yes

Staff member offered woman a method of family planning Yes

No

ACCESSIBILITY

Ease of getting appointment

Very easy

24

Easy

Difficult/very difficult

Convenience of site hours

Very convenient

Convenient

Inconvenient/very inconvenient

Perception of time spent at facility day of abortion procedure Acceptable

Should have spent less time

Should have spent more time

55

43

FACILITY ENVIRONMENT

Facility cleanliness

Very clean

Clean

Dirty/very dirty

26

71

Antichoice protesters outside of facility

Yes

67

No

33

Total

100

tResponses were on a scale of 0 (worst care) to 10 (best care). Notes: Unless otherwise noted, data are percentages. Figure in parentheses is the standard deviation.

Percentages may not add to 100 because of rounding.

When asked whether the doctor made them feel comfortable and whether the nurse and receptionist had treated them with respect, the percentage responding "yes, definitely" ranged from $78 \%$ to $92 \%$. Eighty-three percent rated the staff as "very careful" with their personal and private information. Ratings of the security guard were somewhat less favorable, however; $26 \%$ reported that the security guard had used a rude tone or manner with them.

More than $90 \%$ of the women felt the information they had received about the abortion procedure was sufficient,

*Of the group of women who reported being counseled on family planning but not being offered any methods of family planning $(\mathrm{N}=52), 79 \%$ indicated on a subsequent survey question that they planned to use family planning after their visit. When asked which method they planned to use, all reported plans to select a modern method of family planning. This suggests that these women were interested in using family planning and the fact that they were not offered family planning is not attributable to lack of client interest. and $87 \%$ said the information they had received about how to take care of themselves at home following the abortion was sufficient. In contrast, fewer than half (48\%) reported that a staff member talked with them about potential emotional responses after the abortion. The vast majority of women had confidence in the technical skills of the doctor who had attended them. Most also felt the staff had done enough to control their pain during the abortion (87\%). In terms of postabortion contraceptive services, $88 \%$ of the sample reported that a staff member talked with them about family planning at any visit, and $81 \%$ reported that they were offered a method of family planning. *

Clients thought that service accessibility was good; $24 \%$ said it was very easy to get an appointment at the site, and $60 \%$ said it was easy. Most considered the hours of operation to be convenient. The total time spent at the facility the day of the abortion was rated less favorably, however; 


\begin{tabular}{|c|c|c|c|}
\hline Measure & $\begin{array}{l}\text { Odds ratio } \\
(\mathrm{N}=391)\end{array}$ & Measure & $\begin{array}{l}\text { Odds ratio } \\
(\mathrm{N}=391)\end{array}$ \\
\hline \multicolumn{2}{|l|}{ QUALITY OF CARE } & \multicolumn{2}{|l|}{ Convenience of site hours } \\
\hline Client-staffinteraction & & Very convenient & $2.41(1.43-4.05)^{* *}$ \\
\hline \multicolumn{2}{|l|}{ Doctor made woman feel comfortable } & \multirow[t]{2}{*}{ Convenient/inconvenient/very inconvenient (ref) } & 1.00 \\
\hline Yes, definitely & $3.25(1.67-6.29)^{* * *}$ & & \\
\hline \multirow[t]{2}{*}{ Yes, somewhat/no/no, not at all (ref) } & \multirow[t]{2}{*}{1.00} & \multicolumn{2}{|c|}{ Perception of time spent at facility day of abortion procedure } \\
\hline & & Acceptable & $2.78(1.80-4.28)^{* * *}$ \\
\hline \multicolumn{2}{|c|}{ Nurse treated woman with respect and dignity } & \multirow[t]{2}{*}{ Unacceptable (ref) } & \multirow[t]{3}{*}{1.00} \\
\hline Yes, definitely & $2.15(0.94-4.93)$ & & \\
\hline Yes, somewhat/no/no, not at all (ref) & 1.00 & Facility cleanliness & \\
\hline \multicolumn{2}{|c|}{ Receptionist treated woman with respect and dignity } & Very clean & $1.89(1.16-3.08)^{*}$ \\
\hline Yes, definitely & $1.71(1.03-2.83)^{*}$ & Clean/dirty/very dirty (ref) & 1.00 \\
\hline Yes, somewhat/no/no, not at all (ref) & 1.00 & \multicolumn{2}{|l|}{ Antichoice protesters outside of facility } \\
\hline \multicolumn{2}{|c|}{ Staff care with woman's personal and private information } & Yes & $0.96(0.61-1.52)$ \\
\hline Very careful & $2.48(1.40-4.39)^{* *}$ & No (ref) & 1.00 \\
\hline Somewhat careful/not careful (ref) & 1.00 & SOCIAL AND DEMOGRAPHIC & \\
\hline \multicolumn{2}{|c|}{ Information and counseling } & Age & $1.01(0.98-1.05)$ \\
\hline \multicolumn{2}{|c|}{$\begin{array}{l}\text { Staff provided sufficient information about the abortion } \\
\text { procedure }\end{array}$} & \multicolumn{2}{|l|}{ High school graduate } \\
\hline Yes & $1.79(0.79-4.09)$ & Yes (ref) & 1.00 \\
\hline No (ref) & 1.00 & No & $1.06(0.67-1.68)$ \\
\hline \multirow{2}{*}{\multicolumn{2}{|c|}{$\begin{array}{l}\text { Staff provided sufficient information about self-care } \\
\text { following abortion }\end{array}$}} & \multicolumn{2}{|l|}{ Marital status } \\
\hline & & Unmarried & $1.01(0.64-1.59)$ \\
\hline Yes & $1.90(1.01-3.57)^{*}$ & Married/in civil union (ref) & 1.00 \\
\hline No (ref) & 1.00 & \multicolumn{2}{|l|}{ Parity } \\
\hline \multirow{2}{*}{\multicolumn{2}{|c|}{$\begin{array}{l}\text { Staff talked with woman about how she might feel } \\
\text { emotionally after abortion }\end{array}$}} & 0 & $0.56(0.33-0.95)^{*}$ \\
\hline & & $\geq 1$ (ref) & 1.00 \\
\hline Yes & $1.96(1.27-3.05)^{* *}$ & & \\
\hline No (ref) & 1.00 & \multicolumn{2}{|l|}{$\begin{array}{l}\text { ABORTION VISIT } \\
\text { Site }\end{array}$} \\
\hline Technical competence & & General hospital (ref) & 1.00 \\
\hline Woman felt confident in technical sk & ctor & Maternity hospital & $0.63(0.30-1.34)$ \\
\hline Yes, definitely & $2.46(1.22-4.95)^{*}$ & Primary health center & $1.24(0.70-2.20)$ \\
\hline Yes, somewhat/no/no, not at all (ref) & 1.00 & Abortion procedure & \\
\hline Perception of staff management of & g abortion & Medication abortion & $1.16(0.67-2.04)$ \\
\hline Could have done more to control pain & $0.62(0.33-1.17)$ & Surgical abortion (ref) & 1.00 \\
\hline Did enough to control pain (ref) & 1.00 & Gestational age & $1.05(0.93-1.18)$ \\
\hline Postabortion contraceptive services & & & \\
\hline Staff member offered woman a met & nily planning & Sex of the doctor who performed the abortion & \\
\hline Yes & $0.90(0.49-1.66)$ & Male (ref) & 1.00 \\
\hline No (ref) & 1.00 & Female & $1.49(0.82-2.68)$ \\
\hline Accessibility & & Model chi-square $(d f)=215.11(24)$ & \\
\hline Ease of getting appointment & & & \\
\hline Very easy & $1.53(0.92-2.53)$ & & \\
\hline Easy/difficult/very difficult (ref) & 1.00 & & \\
\hline
\end{tabular}

${ }^{*} \mathrm{p}<.05 .{ }^{* *} \mathrm{p}<.01 .{ }^{* * *} \mathrm{p}<.001$. Note: ref $=$ reference group.

just $55 \%$ found the waiting time acceptable. In terms of the facility environment, the majority rated the facility as clean, and $67 \%$ reported seeing antichoice protesters outside the facility. Of those who saw protesters, $62 \%$ said they were bothered by them (not shown).

\section{Factors Associated with Overall Evaluation of the Service}

In the bivariate analysis, we found that all of the quality of care measures except for women's rating of the security guard's treatment of them were associated with their overall evaluation of the service; more positive ratings on quality were associated with a higher overall evaluation (not shown). Many of the clients' social and demographic and abortion visit characteristics, including age, education, marital status, parity, site, gestational age and the sex of the doctor, were also associated with how they evaluated the service they received. However, the type of abortion procedure received, whether women reported being offered a choice of abortion procedure, whether the current procedure was a follow-up to an incomplete medication abortion, residence and having had a previous induced abortion were not related to how they rated the services.

In the multivariate analysis, women who gave the highest rating on whether the doctor had made them feel com- 
fortable evaluated the overall quality of service as higher than did those who gave lower ratings on that measure (odds ratio, 3.3-Table 3, page 197). Compared with other women, those who gave the highest rating on whether the receptionist had treated them with respect and those who felt the staff had been very careful with their personal and private information gave a higher rating to the service overall (1.7 and 2.5, respectively). Women who felt the staff had provided sufficient information about how to care for themselves at home following the abortion gave higher ratings to the service overall than did those who felt they had not received sufficient information (1.9). Compared with those who had not received counseling from the staff about how they might feel emotionally after the abortion, those who had been counseled gave higher scores to the service overall (2.0). Women who had the most confidence in the technical skills of the doctor who had attended them rated the service more highly (2.5) than those who had less confidence in their doctor's skills.

Measures of service accessibility and the facility environment were associated with the overall service rating. Women who rated the site hours as very convenient, those who felt that the waiting time the day of their abortion visit was acceptable and those who rated the facility as very clean gave higher ratings to the service overall than did other women (odds ratios, 2.4, 2.8 and 1.9, respectively).

The only social and demographic factor associated with overall service evaluations was parity: Women who had had no children gave lower ratings to the service overall than women who had given birth previously (odds ratio, 0.6). No abortion visit factors were significant.

\section{DISCUSSION}

In this study, we sought to understand how women view the quality of care provided in Mexico City's public-sector legal abortion program, and the range of factors that contribute to women's overall evaluation of the service. We found that the quality of care is generally viewed favorably. High proportions of women said they were treated well by the staff, that the service was easy to access, that the facility was clean and that the doctor who attended them was technically skilled. High proportions also felt they had received adequate pain management and sufficient information about the procedure and self-care at home afterwards. The proportion reporting that they had been offered postabortion contraceptives was also high.

These results suggest that the service is doing a reasonably good job from the perspective of the clientele. Although the overall picture is positive, our results do point to some areas in which improvements can be made. For example, almost half of the women in our study rated the waiting time as unacceptable, and only $48 \%$ reported that the staff had talked with them about emotions they might experience after the abortion.

With respect to our second objective of understanding the factors that contributed to women's overall evaluation of care, we found that, as in previous studies, ${ }^{22-24}$ women's evaluation of abortion care was strongly associated with ratings of the client-staff interaction. Women valued the doctor's efforts to help them feel comfortable, the staff's respect for their privacy and respectful treatment by the receptionists. Given the sensitive nature of abortion care and the fact that women may feel vulnerable to receiving judgmental treatment, it is not surprising that these factors emerged as important. The behavior of staff other than doctors was associated with women's overall care evaluation, suggesting that efforts to improve quality of care should focus on how all members of the staff, not just clinical staff, treat patients.

As in previous studies, ${ }^{22,25}$ the perceived adequacy of information and counseling women received was associated with women's overall evaluation of care. Service evaluation was more positive among those who felt they received sufficient information about how to take care of themselves at home following the abortion. An additional counseling variable that was significant was staff talking with women about how they might feel emotionally after the abortion. This most likely reflects the strong stigma still attached to abortion in Mexico, and women may feel they are violating cultural and social norms by terminating a pregnancy. ${ }^{39}$ Staff provision of emotional and psychological information and support may be helpful, since women may not have anyone else with whom they feel comfortable discussing their abortion. A practical recommendation is that abortion care staff should routinely incorporate information about postabortion emotions into their counseling practices, but it is critical that any information provided on postabortion mental health be evidence based. ${ }^{40}$

As in other studies, service accessibility and features of the facility environment were associated with women's overall evaluation of care. ${ }^{22,23}$ One accessibility issue that we did not measure was women's feeling about the length of time it took to get their appointment. This factor was found to be of high importance to patients receiving abortion care in a previous study ${ }^{41}$ and should be investigated further. We note, however, that the convenience of the hours, the waiting time at the care site and the cleanliness of facility were all associated with women's overall service evaluation, suggesting that these factors should be targeted in quality improvement efforts. Women's reports about whether they saw abortion protesters at the site did not correlate with their overall views of the service. This may indicate that women differentiate between what happens outside the facility and what happens inside, as others have suggested. ${ }^{22}$ It also is possible that protesters may be problematic for certain women, but not all.

Despite the fact that clients may have a limited ability to evaluate the technical competence of their doctors, ${ }^{37}$ it is interesting that their confidence in the technical skills of their doctor was associated with their overall rating of care. Given that abortion was highly restricted in Mexico City until recently, women may have had personal experiences with illegal abortions and may have heard stories of 
botched illegal abortions. Feeling assured of the technical competence of the abortion provider may be especially important in this context.

In contrast with studies that found that age, education and marital status are associated with abortion care satisfaction, ${ }^{22,25,26}$ parity was the only social and demographic characteristic associated with women's overall evaluation of abortion care in this study. Women who had never given birth rated their care less favorably than those who had, possibly because women who have given birth previously may be more accustomed to pregnancy, gynecologic procedures and pain. According to a previous study on medication abortion in four countries of Latin America, women who had never given birth considered the abortion more painful and were more worried and anxious during the procedure than women who had, and therefore rated their abortion experience more negatively. ${ }^{28}$

Unlike several previous studies, ${ }^{24,29,30}$ our research did not find differences in overall ratings of care by type of abortion procedure or by site of care. Our finding that care was evaluated just as favorably at the primary health center as at the hospitals is important because it indicates that expanding abortion care at the primary health level, a decision that may improve efficiency and reduce the costs of the service, ${ }^{42}$ will not lead to reductions in patient satisfaction.

Those who had incomplete medication abortions did not rate the service quality more poorly than those who had complete abortions, a finding that differs from results of some previous research. ${ }^{28}$ It is possible that women in the current study were aware of this possibility because they had received sufficient counseling. Moreover, the overall service quality rating among women who reported being offered a choice of abortion procedures was not significantly different from the rating among those not offered a choice. Choice of abortion procedure has been identified as a dimension of patient-centered abortion care $^{35}$ and has been linked to patient satisfaction. ${ }^{30}$ We speculate that the circumstances in Mexico City at the time of our study, shortly after abortion was legalized, may play a role in the importance of this factor. It is possible that the choice between abortion methods was less important for women in our study than the choice between a safe, legal abortion and a clandestine, potentially unsafe abortion. Furthermore, because legal abortion is a relatively new service, women may not have been aware that two types of abortion procedures exist; they also may not have expected to receive any choices regarding their care because they were receiving services in the public sector, and for most the service was free of charge. More research is needed to understand how clients view having a choice of abortion procedure.

Our study has several limitations. Because all of our data collection took place on-site at the facilities in which women received their abortion care, women's responses may have been affected because they did not feel comfortable criticizing the care. We tried to reduce the effects of such discomfort by conducting the interviews in private and by reassuring women that their comments would not be shared with the staff. Another limitation is the generalizability of our results. Our study was carried out at three of the public-sector sites that were providing abortion services at the time; the experiences of women at these sites may have been different from those at other public-sector sites, particularly those with lower client volumes. Our sample was also limited to adults; $6 \%$ of the women seeking legal abortion care are minors, ${ }^{43}$ and the experiences of these younger women may be different from the experiences of the adults in our sample. In addition, we were unable to interview women who received medication abortions but who failed to return for their follow-up appointments. Preliminary data from the Ministry of Health suggests that approximately $10 \%$ of women who seek medication abortions do not return for their follow-up visits. ${ }^{33}$

In conclusion, our findings add to the body of evidence documenting the overall quality of services provided in Mexico City's legal abortion program and contribute important information for the monitoring and evaluation of the policy. Although our study results are positive, it is important to recognize that quality of care should be evaluated from various perspectives, not only those of clients. Future studies should explore the perspectives of providers and policymakers, and should examine constraints to providing high quality care, such as lack of resources and staff. We also recommend that qualitative research on abortion service quality be conducted with women receiving care where the categories of quality are generated by women themselves, not by researchers. This may provide insights into issues important to women that are missing from abortion quality-of-care frameworks. Research on patients' experiences with private-sector abortion care in Mexico City is also a priority. Data are not routinely collected on private-sector abortions, but a recent study with a sample of private abortion providers identified deficiencies in service quality. ${ }^{44}$ Finally, we recommend studies to assess the cost-effectiveness of the abortion reform in Mexico City and to measure the impact this reform has had for women's health and well-being.

\section{REFERENCES}

1. Langer-Glas A, Unwanted pregnancy and unsafe abortion: its impact on health in Mexico, Gaceta Médica de México, 2003, 139(Suppl. 1):S3-S7 (in Spanish)

2. Schiavon R, Polo G and Troncoso E, Aportes para el debate sobre la despenalización del aborto, Mexico City: Ipas, 2007.

3. Juárez F et al., Estimates of induced abortion in Mexico: What's changed between 1990 and 2006? International Family Planning Perspectives, 2008, 34(4):158-168.

4. Sánchez Fuentes ML, Paine J and Elliott-Buettner B, The decriminalisation of abortion in Mexico City: How did abortion rights become a political priority? Gender and Development, 2008, 16(2):345-360.

5. Human Rights Watch, The Second Assault: Obstructing Access to Legal Abortion After Rape in Mexico, New York: Human Rights Watch, 2006.

6. Rao KA and Faúndes A, Access to safe abortion within the limits of the law, Best Practice \& Research Clinical Obstetrics and Gynaecology, 2006, 20(3):421-432. 
7. Ganatra B and Elul B, Legal but not always safe: three decades of a liberal abortion policy in India, Gaceta Médica de México, 2003, 139(Suppl. 1):S103-S108.

8. Office of Registrar General, India, Sample Registration System, Maternal Mortality in India 1997-2003: Trends, Causes and Risk Factors, New Delhi: Registrar General, India, 2006.

9. Jewkes RK et al., Why are women still aborting outside designated facilities in metropolitan South Africa? BJOG, 2005, 112(9):12361242.

10. World Health Organization (WHO), Safe Abortion: Technical and Policy Guidance for Health Systems, Geneva: WHO, 2003.

11. Kols AJ and Sherman JE, Family planning programs: improving quality, Population Reports, 1998, Series J, No. 47.

12. Billings DL, Fuentes Velásquez J and Pérez-Cuevas R, Comparing the quality of three models of postabortion care in public hospitals in Mexico City, International Family Planning Perspectives, 2003, 29(3):112-120.

13. Bhandari A et al., Experiences of abortion in Nepal and menstrual regulation in Bangladesh: a gender analysis, Gender and Development, 16(2):257-272.

14. Huntington D, Meeting women's health care needs after abortion: lessons from operations research, in: Warriner IK and Shah IH, eds., Preventing Unsafe Abortion and Its Consequences: Priorities for Research and Action, New York: Guttmacher Institute, 2006, pp. 93-113.

15. Johnson BR et al., Reducing unplanned pregnancy and abortion in Zimbabwe through postabortion contraception, Studies in Family Planning, 2002, 33(2):195-202.

16. van Dijk MG et al., Women's experiences with legal abortion in Mexico City: a qualitative study, Studies in Family Planning, 2011, 42(3):167-174

17. Troncoso E, Palermo TM and Ortiz O, Barriers to legal abortion services in Mexico City: women's perspectives, paper presented at the annual meeting of the American Public Health Association, Philadelphia, PA, USA, Nov. 7-11, 2009.

18. Lara D et al., Access to legal abortion of rape-related pregnancy in Mexico City, Gaceta Médica de México, 2003, 139(Suppl. 1):S77-S90 (in Spanish)

19. Lara D et al., Challenges accessing legal abortion after rape in Mexico City, Gaceta Médica de México, 2006, 142(Suppl. 2):85-89.

20. Elu MC, Between political debate and women's suffering: abortion in Mexico, in: Mundigo AI and Indriso C, eds., Abortion in the Developing World, London: WHO and Zed Books, 1999, pp. 245-258.

21. Langer A et al., Improving post-abortion care in a public hospital in Oaxaca, Mexico, Reproductive Health Matters, 1997, 5(9):20-28

22. Zapka JG et al., The silent consumer: women's reports and ratings of abortion services, Medical Care, 2001, 39(1):50-60.

23. Picker Institute and Kaiser Family Foundation, From the patient's perspective: quality of abortion care, 1999, <http://www.kff.org/ womenshealth/1475-index.cfm>, accessed June 29, 2011.

24. Slade P et al., Termination of pregnancy: patients' perceptions of care, Journal of Family Planning and Reproductive Health Care, 2001, 27(2):72-77.

25. Oliveras E, Larsen U and David PH, Client satisfaction with abortion care in three Russian cities, Journal of Biosocial Science, 2005, 37(5):585-601.

26. Bulut A and Toubia N, Abortion services in two public sector hospitals in Istanbul, Turkey: How well do they meet women's needs? in Mundigo AI and Indriso C, eds., Abortion in the Developing World, London: WHO and Zed Books, 1999, pp. 259-278.

27. Lie ML, Robson SC and May CR, Experiences of abortion: a narrative review of qualitative studies, BMC Health Services Research, 2008 , 8:150

28. Lafaurie MM et al., Women's perspectives on medical abortion in Mexico, Colombia, Ecuador and Peru: a qualitative study, Reproductive Health Matters, 2005, 13(26):75-83.
29. Sihvo S et al., Quality of care in abortion services in Finland, Acte Obstetricia et Gynecologica Scandinavica, 1998, 77(2):210-217.

30. Rørbye C, Nørgaard M and Nilas L, Medical versus surgical abortion: comparing satisfaction and potential confounders in a partly randomized study, Human Reproduction, 2005, 20(3):834-838.

31. Secretaría de Salud del Distrito Federal, 2009 Agenda Estadística 2010, <http://www.salud.df.gob.mx/ssdf/media/Agenda_2009/ index.html>, accessed June 29, 2011

32. Sanhueza P et al., Introducing medical abortion in the public health sector in Mexico, International Journal of Gynaecology $\mathcal{E}$ Obstetrics, 2009, 107(Suppl. 2):S72.

33. Secretaría de Salud del Distrito Federal, Mexico's Federal District (DF) Ministry of Health Program for Legal Abortion, 2008, Mexico City: Secretaría de Salud del Distrito Federal, 2008.

34. Leonard AH and Winkler J, A quality of care framework for abortion care, Advances in Abortion Care, 1991, 1(1):1-4.

35. Hyman A and Kumar A, A woman-centered model for comprehensive abortion care, International Journal of Gynaecology $\&$ Obstetrics, 2004, 86(3):409-410

36. Consumer Assessment of Healthcare Providers and Systems (CAHPS), CAHPS clinician and group survey reporting kit, 2008 <http:// www.cahps.ahrq. gov/CAHPSkit/CG/CGChooseQx.asp>, accessed June 29, 2011.

37. Lewis JR, Patient views on quality care in general practice: literature review, Social Science $\&$ Medicine, 1994, 39(5):655-670.

38. Long JS and Freese J, Regression Models for Categorical Dependent Variables Using Stata, second ed., College Station, TX: StataCorp, 2006

39. Amuchástegui Herrera A and Rivas Zivy M, Clandestine abortion in Mexico: a question of mental as well as physical health, Reproductive Health Matters, 2002, 10(19):95-102.

40. Major B et al., Abortion and mental health: evaluating the evidence, American Psychologist, 2009, 64(9):863-890

41. Wiebe ER and Sandhu S, Access to abortion: what women want from abortion services, Journal of Obstetrics and Gynaecology Canada, 2008, 30(4):327-331.

42. Hu D et al., Cost-effectiveness analysis of alternative first-trimester pregnancy termination strategies in Mexico City, BJOG, 2009 $116(6): 768-779$

43. Sanhueza P, Experiencias de la secretaria de salud con el programa de interrupción legal del embarazo, in: Freyermuth $G$ and Troncoso E, eds., El Aborto: Acciones Medicas y Strategias Sociales, Mexico City: Comité por un Maternidad Sin Riesgos y IPAS, 2008, pp 77-79.

44. Schiavon R et al., Characteristics of private abortion services in Mexico City after legalization, Reproductive Health Matters, 2010 , 18(36):127-135.

\section{RESUMEN}

Contexto: Se legalizó el aborto inducido en el primer trimestre en la Ciudad de México en 2007. Sin embargo, se sabe muy poco sobre las percepciones de las clientas de los servicios de aborto disponibles en las instituciones del sector público.

Métodos: Las percepciones de la calidad de atención se midieron en 402 mujeres de 18 años o mayores que habian tenido un aborto en alguno de los tres instituciones públicos en la Ciudad de México en 2009. Se evaluaron seis aspectos de la calidad de atención (interacción clienta-personal, provisión de información, competencia técnica, servicios anticonceptivos postaborto, accesibilidad y ambiente de la institución). También se llevó a cabo un análisis de regresión logística ordinal para identificar cuáles aspectos eran importantes para las mujeres en la evaluación general de la atención. 
Resultados: Las clientas otorgaron altas calificaciones a los servicios en general, con un promedio de 8.8 de 10. En análisis multivariados, las calificaciones generales fueron más altas en mujeres que dijeron que el médico las hizo sentir cómodas (razón de momios, 3.3), la recepcionista fue respetuosa (1.7), el personal tuvo cuidado de proteger su privacidad (2.5), había recibido suficiente información sobre el autocuidado en casa después del aborto y sobre las emociones postaborto (1.9 y 2.0, respectivamente), así como que sintieron confianza en las habilidades técnicas del médico (2.5). Las calificaciones del horario del sitio como muy conveniente (2.4), el tiempo de espera como aceptable (2.8) y el hecho de que las institutiones estaban muy limpias (1.9), estuvieron asociadas con altas calificaciones en general. En general, en comparación con las mujeres que ya habian dado a luz, aquellas que no lo habian hecho dieron a los servicios una calificación más baja (0.6).

Conclusión: Los esfuerzos para mejorar las experiencias de las pacientes de los servicios de aborto deben enfocarse en las cinco aspectos que resultaron ser de significancia estadística: la interacción clienta-personal, provisión de información, accesibilidad del servicio, competencia técnica y el ambiente de la institución. El factor más importante parece ser el hecho de si el médico hace sentir cómoda a la mujer durante su visita.

\section{RÉSUMÉ}

Contexte: En 2007, l'IVG du premier trimestre a été légalisée à Mexico. Une recherche limitée a été menée pour comprendre les perceptions des clientes des services d'avortement proposés dans les établissements du secteur public.

Méthodes: Les perceptions de qualité des soins ont été mesurées parmi 402 femmes âgées de 18 ans ou plus qui s'étaient fait avorter dans l'un de trois établissements publics de la ville de Mexico en 2009. Six domaines de qualité (interaction entre la cliente et le personnel, apport d'information, compétence technique, services contraceptifs post-IVG, accessibilité et environnement de l'établissement) ont été évalués. Ceux impor- tants dans l'évaluation globale des femmes ont été identifiés par analyse de régression logistique ordinale.

Résultats: Les clientes ont évalué généreusement les services globaux reçus, atteignant une moyenne de 8,8 sur 10. Dans l'analyse multivariée, les évaluations globales se sont avérées supérieures parmi les femmes ayant déclaré que le médecin les avait mises à l'aise $(O R, 3,3)$, que la réceptionniste les avait traitées avec respect $(1,7)$, que le personnel s'était montré très soucieux de protéger leur confidentialité (2,5), qu'elles avaient reçu suffisamment d'information sur les soins nécessaires après le retour à domicile et sur les émotions post-IVG (1,9 et 2,0, respectivement) et qu'elles avaient eu confiance en la compétence technique du médecin (2,5). Les évaluations d'heures d'ouverture fort commodes $(2,4)$, de temps d'attente acceptable $(2,8)$ et de grande propreté de l'établissement $(1,9)$ sont toutes associées aux cotes globales supérieures. Par rapport aux femmes qui avaient accouché, l'évaluation globale des services par celles qui s'étaient fait avorter s'est avérée inférieure $(0,6)$.

Conclusion: Les efforts d'amélioration de l'expérience des patientes des services d'IVG doivent se concentrer sur l'interaction entre la cliente et le personnel, l'apport d'information, l'accessibilité des services, la compétence technique et l'environnement au sein de l'établissement. Le facteur jugé le plus important semble être si le docteur met la femme à l'aise ou non lors de sa visite.

\section{Acknowledgments}

This study was funded by the Charlotte Ellertson Social Science Postdoctoral Fellowship in Abortion and Reproductive Health. The authors wish to thank the Mexico City Ministry of Health, in particular Dr. Armando Ahued Ortega, for collaborating on this research; Elisa Azcarraga, Vanessa Cravioto and Yvonne Flores for assistance with data collection; Marieke van Dijk and Maya Blum for helpful input on the study protocol; and Abby Krumholz for editorial support.

Author contact:davidab@usc.edu 